\title{
The role of genetics in pre-eclampsia and potential pharmacogenomic interventions
}

This article was published in the following Dove Press journal:

Pharmacogenomics and Personalized Medicine

19 January 2012

Number of times this article has been viewed

\author{
Paula Juliet Williams \\ Linda Morgan \\ Human Genetics Research \\ Group, University of Nottingham, \\ Nottingham, UK
}

Correspondence: Paula Juliet Williams Human Genetics Research Group, School of Molecular Medical Sciences, University of Nottingham, A Floor West Block, Queen's Medical Centre, Nottingham NG7 2UH, UK

Tel +44 II5 8230758

Fax +44 II 8230759

Email paula.williams@nottingham.ac.uk

\begin{abstract}
The pregnancy-specific condition pre-eclampsia not only affects the health of mother and baby during pregnancy but also has long-term consequences, increasing the chances of cardiovascular disease in later life. It is accepted that pre-eclampsia has a placental origin, but the pathogenic mechanisms leading to the systemic endothelial dysfunction characteristic of the disorder remain to be determined. In this review we discuss some key factors regarded as important in the development of pre-eclampsia, including immune maladaptation, inadequate placentation, oxidative stress, and thrombosis. Genetic factors influence all of these proposed pathophysiological mechanisms. The inherited nature of pre-eclampsia has been known for many years, and extensive genetic studies have been undertaken in this area. Genetic research offers an attractive strategy for studying the pathogenesis of pre-eclampsia as it avoids the ethical and practical difficulties of conducting basic science research during the preclinical phase of pre-eclampsia when the underlying pathological changes occur. Although pharmacogenomic studies have not yet been conducted in pre-eclampsia, a number of studies investigating treatment for essential hypertension are of relevance to therapies used in pre-eclampsia. The pharmacogenomics of antiplatelet agents, alpha and beta blockers, calcium channel blockers, and magnesium sulfate are discussed in relation to the treatment and prevention of pre-eclampsia. Pharmacogenomics offers the prospect of individualized patient treatment, ensuring swift introduction of optimal treatment whilst minimizing the use of inappropriate or ineffective drugs, thereby reducing the risk of harmful effects to both mother and baby.
\end{abstract}

Keywords: pre-eclampsia, pharmacogenetics, placenta, trophoblast, genetics

\section{Introduction}

One of the major aims of the human genome project and subsequent disease initiatives was the discovery of new pharmaceutical targets. With the current advances in our understanding of genetics and the ever-improving sequencing technologies available we are now at an exciting time not just for research, but also for the translation of research results into potential health benefits due to the evolution of pharmacogenomics and the development of personalized medicine. The focus of this review is to provide a comprehensive overview of the genetic and pharmacogenetic aspects of pre-eclampsia. An in-depth review of the pathophysiology of the disorder is outside the scope of this review. ${ }^{1}$

Genetic involvement in the pregnancy-specific condition pre-eclampsia has long been recognized but determining the mode of inheritance and the genes involved has not been straightforward. Research is continuing to unravel the genetic component of pre-eclampsia, aiding understanding of the pathophysiological changes that 
occur in this disorder. The importance of these findings in understanding the pathogenesis of pre-eclampsia cannot be overstated. The trigger for pre-eclampsia arises in the placental bed early in pregnancy, at a time and location that precludes basic science research for ethical and practical reasons. Molecular genetics research can therefore provide clues to the primary causes of pre-eclampsia that are unavailable by other methods. Potential opportunities for pharmacogenomic interventions are considered in the light of evidence from other related diseases.

\section{The impact of pre-eclampsia}

Pre-eclampsia is a leading cause of maternal and perinatal morbidity and mortality, affecting between $0.4 \%$ and $2.8 \%$ of all pregnancies in developed countries and many more in developing countries, leading to over 8 million cases worldwide per year. ${ }^{2}$ Although the definition of preeclampsia focuses on the occurrence of hypertension and proteinuria, this is a multisystem disorder that may affect the brain, lungs, kidney, and liver. Not only does pre-eclampsia impact on maternal health but the growth and development of the fetus are frequently compromised, and pre-eclampsia has long-term impacts on the health of both the mother and offspring. ${ }^{3-5}$ A two-stage model for pre-eclampsia has been proposed. ${ }^{6}$ The first stage is reduced placental perfusion, secondary to abnormal implantation and development of placental vasculature. The second stage is the maternal response to this condition, characterized by widespread inflammation and maternal endothelial cell dysfunction. ${ }^{7}$ A number of pregnant women have pre-existing risk factors that make them more susceptible to the development of preeclampsia and the other hypertensive disorders of pregnancy (see Table 1).

Studies examining plasma and tissue samples following the onset of pre-eclampsia have confirmed the presence of oxidative stress, and the release of endothelial proteins and pro-inflammatory cytokines, ${ }^{8}$ but discriminating between causal factors and secondary responses presents significant challenges. In this regard, genetic studies of pre-eclampsia offer an advantage in that genotype remains constant and is not affected by the disease process.

\section{Genetic basis of pre-eclampsia}

Genetic studies of pre-eclampsia have been confounded by the problem that there is currently no universally accepted definition of the disorder, with several internationally recognized definitions available. ${ }^{9}$ The general consensus diagnosis of pre-eclampsia is a blood pressure of $\geq 140 / 90 \mathrm{mmHg}$
Table I Risk factors for pre-eclampsia

\begin{tabular}{ll}
\hline Risk factors for pre-eclampsia \\
Immunological & Nulliparity \\
& Primipaternity \\
& Donor sperm/oocyte \\
In vitro fertilization treatment & Multiple pregnancy \\
Obstetric & Previous adverse obstetric \\
& history - gestational hypertension, \\
& pre-eclampsia, fetal growth restriction, \\
& abruption placentae, perinatal death \\
& Chronic hypertension \\
& Renal disease \\
Pre-existing conditions & Type 2 diabetes \\
& Thrombophilia syndromes \\
& Autoimmune disorder \\
& Resistance index 0.58 \\
& Presence of diastolic notch \\
Ebnormal uterine Doppler & Black ethnicity \\
Maternal factors & Obesity \\
&
\end{tabular}

measured on at least two occasions separated by 6 hours after the twentieth week of pregnancy in a previously normotensive woman, accompanied by significant proteinuria $(300 \mathrm{mg} / \mathrm{L}$ or $500 \mathrm{mg} / 24$ hours) in the absence of a urinary tract infection. ${ }^{9}$ In pre-eclampsia the elevated blood pressure returns to normal 6 to 12 weeks following delivery. Pre-eclampsia can progress rapidly, at times without warning, to the lifethreatening convulsive condition eclampsia. Development of pre-eclampsia begins with a loss of vascular refractoriness to vasoactive agents followed by vasoconstriction, resulting in a decrease in intravascular volume. Fluid is then passed across the "leaky" capillaries to the extravascular space. Pre-eclampsia is subsequently characterized by a generalized dysfunction of the maternal endothelium ${ }^{10}$ with impairment of endothelium-dependent relaxation in maternal resistance arteries. $^{11}$

A genetic component for pre-eclampsia has been indicated since the observation in the nineteeth century of a clustering of cases within families. ${ }^{12}$ Challenges to defining this genetic involvement include the fact that the phenotype is expressed only in parous females, and also the need to evaluate the genotypes of both the mother and her fetus.

\section{Pre-eclampsia is a complex genetic disorder}

It is now accepted that pre-eclampsia is a complex genetic disorder, occurring as the result of variants at different loci, which individually have small effects but collectively contribute to an individual's susceptibility to disease. It is 
probable that no single gene or variant will be identified that is responsible for all cases of pre-eclampsia, although different variants may prove to be associated with subsets of disease, such as early onset pre-eclampsia with fetal growth restriction. In agreement with this is the recent study that identifies three separate subgroups of pre-eclampsia based on expression of plasma membrane proteins involved in angiogenesis (group 1), mitogen-activated protein kinase signaling (group 2), and hormone biosynthesis and metabolism (group 3). ${ }^{13}$ Environmental factors, such as psychological stress ${ }^{14}$ and vitamin D deficiency, ${ }^{15}$ also modify an individual's risk of developing pre-eclampsia, determining whether variants with low penetrance result in phenotypic manifestation of the disease.

\section{Deciphering the relative contribution of fetal and maternal genes}

Investigation of both fetal and maternal genotypes is essential to better our understanding of the genetics of pre-eclampsia. An undisputable role of the placenta in the primary pathogenesis of pre-eclampsia is clear, indicating a fetal contribution to susceptibility to the disorder. ${ }^{16}$ Placental development in pre-eclampsia is superficial. Normal placental development is characterized by invasion of cytotrophoblast cells into the maternal decidua and inner third of the myometrium. Cytotrophoblast invasion serves to anchor the placenta to the wall of the uterus and also to gain access to the maternal vasculature. Endovascular trophoblast invasion enables the onset of placental circulation. The endovascular trophoblast cells also serve to trigger the process of physiologic conversion which is characterized by a loss of elastic fibers and smooth muscle cells due to proteolytic activity of the invasive endovascular trophoblast cells. Furthermore, spiral artery walls are replaced by intramural fibrin and fibrinoid, which is produced by the trophoblast cells, resulting in a considerable increase in the luminal diameter. These changes serve to transform the originally flexible vessels into rigid high-capacitance vessels which are incapable of constricting. Both extravillous and endovascular cytotrophoblast invasion is deficient in pre-eclampsia resulting in spiral arteries retaining their original architecture which precludes an adequate vascular response to the demands from the fetus for increased blood flow. ${ }^{17}$ Decreased expression of laminin receptor 1 by cytotrophoblasts and syncytiotrophoblasts has been found in pre-eclampsia which may have a role in the shallow trophoblastic invasion in pre-eclampsia. ${ }^{18} \mathrm{~A}$ role for paternally inherited fetal genes in the determination of clinical phenotype is evident from reports of higher rates of pre-eclampsia in pregnancies fathered by men who were born of a pre-eclamptic pregnancy. ${ }^{16,19}$

It has been suggested that an excessive or atypical maternal immune response to invading trophoblast may be the cause of the placental stage of pre-eclampsia, resulting in impaired decidualization and placentation. Thus, preeclampsia can be considered a disease of failed interaction between two genetically different organisms. The genetic conflict hypothesis states that the fetal genetic component comprised of paternal genes functions to enhance the growth and development of the fetus by maximizing nutrient transfer to the fetus. In conflict with this, the maternal genes function to limit transfer to the fetus to ensure that no compromise is made to maternal health. ${ }^{20}$ Fetal genes are predicted to raise maternal blood pressure in order to enhance uteroplacental blood flow, whereas maternal genes act to oppose this. Endothelial dysfunction in pre-eclamptic mothers could, therefore, be interpreted as a fetal attempt to compensate for an inadequate uteroplacental nutrient supply by increasing maternal blood pressure. The Genetics of Pre-eclampsia consortium highlighted the need for examination of both maternal and fetal genotypes performing transmission of disequilibrium testing in both maternal and fetal triads. ${ }^{21}$ Interpreting the relative contribution and interactive effects of both maternal and fetal genes on pre-eclampsia has not been straightforward, but statistical methods are now becoming available. ${ }^{22}$ Unraveling the maternal and fetal genetic contributions to pre-eclampsia will require very large sample sizes, with the development of new statistical algorithms to aid with data analysis, including a multinomial modeling approach that allows the estimation of such genetic effects using either case/mother duos or case/parent trios. ${ }^{23}$

\section{Candidate gene studies of pre-eclampsia}

Over 70 candidate genes selected on the basis of prior biological knowledge of the pathological changes in preeclampsia have been investigated. Candidate genes studied to date can be separated into groups based on their suggested pathophysiological mechanisms: vasoactive proteins, thrombophilia and hypofibrinolysis, oxidative stress and lipid metabolism, endothelial injury, and immunogenetics (see Table 2). ${ }^{24}$ In spite of the large research effort, no candidate gene has been universally accepted as a causal gene for pre-eclampsia. Whilst this may be due in part to ethnic variations within study populations and inconsistency in the definition of pre-eclampsia, the major reason is the fact that the majority of candidate gene studies have been 
Table 2 Candidate genes and predominant polymorphisms implicated in the pathogenesis of pre-eclampsia

\begin{tabular}{|c|c|c|c|}
\hline Proposed mechanism & Gene name & Gene symbol & Polymorphism \\
\hline \multirow[t]{2}{*}{ Vasoactive proteins } & Angiotensinogen & AGT & 235 Met $>$ Thr \\
\hline & Angiotensin converting enzyme & $A C E$ & I/D intron 16 \\
\hline \multirow[t]{5}{*}{ Thrombophilia and hypofibrinolysis } & Factor V Leiden & F5 & $506 \mathrm{Gln}>\mathrm{Arg}$ \\
\hline & Methylenetetrahydrofolate reductase & MTHFR & C667T \\
\hline & Prothrombin & F2 & G20210A \\
\hline & Plasminogen activator factor-I & SERPINEI & Promoter insertion/deletion \\
\hline & Integrin glycoprotein IIla & GPIIIA & C98T \\
\hline \multirow[t]{3}{*}{ Oxidative stress and lipid metabolism } & Apolipoprotein E & $A P O E$ & C886T \\
\hline & Microsomal epoxide hydrolase & $E P H X$ & $\mathrm{II} 3 \mathrm{Tyr}>\mathrm{His}$ \\
\hline & Glutathione-S-transferase & GST & A3I3G \\
\hline \multirow[t]{3}{*}{ Endothelial function } & Endothelial nitric oxide synthase 3 & eNOS3 & 298Glu $>$ Asp \\
\hline & Vascular endothelial growth factor receptor I & VEGFRI & TG repeat \\
\hline & Vascular endothelial growth factor & VEGF & C936T \\
\hline \multirow[t]{2}{*}{ Immunogenetics } & Tumour necrosis factor $\alpha$ & $T N F$ & G-308A \\
\hline & Interleukin 10 & ILIO & GI082A \\
\hline
\end{tabular}

grossly underpowered to detect variants with small effects. It is only in recent years that the small effect size of causal variants has become appreciated in the study of complex genetic disorders, with the majority of variants increasing disease risk by $<50 \%$. Candidate gene studies are further limited by their reliance on our incomplete understanding of the pathogenic processes that occur in pre-eclampsia, which therefore restricts the genes that are evaluated.

\section{Clotting cascade abnormalities}

The occurrence of thrombophilias is well documented in women with pre-eclampsia. ${ }^{25}$ Establishment of the uteroplacental circulation is crucial in determining the success of pregnancy. Thrombophilias are believed to heighten the risk of placental insufficiency due to the formation of placental thrombi, in addition to having direct effects on trophoblast growth and differentiation. ${ }^{26}$ Whether the procoagulant state which characterizes pre-eclampsia is present before a pre-eclamptic pregnancy or whether it is rather a result of damage initiated during placentation remains unclear. The thrombophilic factors methylenetetrahydrofolate reductase, factor V Leiden variant, and prothrombin have been investigated in numerous candidate gene studies. These have yielded conflicting results with the majority of studies showing no association with pre-eclampsia, ${ }^{24,27,28}$ which have been further confirmed by two large meta-analyses..$^{29,30}$

\section{Regulation of endothelial function and hemodynamics}

Due to the role of the renin-angiotensin system in regulating the renal and cardiovascular changes that occur during pregnancy this system has been implicated in the pathophysiology of pre-eclampsia. A number of candidate gene studies, concentrating mainly on angiotensin converting enzyme (ACE), angiotensin II type 1 and type 2 receptor, and angiotensinogen, have yielded inconclusive results. Meta-analyses have implicated the $\mathrm{T}$ allele of angiotensinogen M235T and the deletion allele of the ACE I/D polymorphism..$^{31,32}$

Endothelial nitric oxide synthase 3 has decreased activity in pre-eclampsia. ${ }^{33}$ This enzyme is important for the production of nitric oxide (NO), an important regulator of vasodilatation and vascular remodeling. Genetic association studies of endothelial nitric oxide synthase 3 variants in different ethnic populations have produced conflicting results, and a recent meta-analysis has shown no association with pre-eclampsia. ${ }^{31}$

Vascular endothelial growth factor (VEGF) has also been implicated in the pathophysiological changes of pre-eclampsia due to its role in regulating endothelial cell function and vascular permeability. Two small studies have suggested that the VEGF $405 \mathrm{G}>\mathrm{C}$ and $936 \mathrm{C}>\mathrm{T}$ alleles are associated with pre-eclampsia; results await confirmation in larger studies. ${ }^{34}$ The soluble fms-like tyrosine kinase 1 (sFLT1) located on 13q12, binds VEGF with high affinity thus preventing VEGF from interacting with its receptor VEGFR1, resulting in decreased bioavailability of VEGF. The incidence of trisomy 13 is 2.3 in 10,000 births in pregnancies with pre-eclampsia in comparison with 0.5 in 10,000 births in pregnancies without pre-eclampsia. ${ }^{35}$ It is suggested that the extra copy of chromosome 13 in trisomy 13 results in increased levels of sFLT1, explaining the increased incidence of pre-eclampsia in women carrying trisomy 13 conceptuses. ${ }^{36}$ 


\section{Oxidative stress and lipid metabolism}

Oxidative stress is central to the pathogenesis of preeclampsia. ${ }^{37}$ During the first trimester of pregnancy placental development is in relatively hypoxic conditions, thereby protecting fetal DNA from the harmful effects of damaging free radicals. ${ }^{38}$ Between gestational weeks 8 and 12 extravillous trophoblast plugs are released allowing maternal perfusion of the placenta. ${ }^{39}$ This leads to a sudden burst of oxidative stress. In normal pregnancy oxidative damage is prevented by the expression of antioxidant enzymes including glutathione peroxidase, catalase, and various forms of superoxide dismutase. ${ }^{40,41}$ Expression of these antioxidant enzymes is reduced in the pre-eclamptic placenta leading to a cascade of events which result in impaired placental development. The reduced antioxidant protection in pre-eclampsia culminates in inadequate inactivation of harmful reactive oxygen species (ROS) which cause endothelial dysfunction through lipid peroxidation. ${ }^{42}$ Only a small number of genes involved in regulating oxidative stress have been examined in pre-eclampsia, including epoxide hydrolase and glutathione-S-transferase, and none has been clearly shown to increase susceptibility. ${ }^{43-45}$

Abnormal lipid profiles are a characteristic feature of pre-eclampsia, including the increase in lipid peroxidation brought about by increased oxidative stress. Two major regulators of lipid metabolism, lipoprotein lipase (LPL) and apolipoprotein, are abundantly expressed in the placenta and have been investigated as candidate genes for pre-eclampsia. ${ }^{46-48}$ The Asn291Ser mis-sense mutation in LPL has been associated with lowered plasma LPL activity and increased dyslipidemia in pre-eclampsia, ${ }^{47}$ but other researchers have failed to confirm these findings. ${ }^{49}$

\section{Immune system involvement in pre-eclampsia}

The fetus is hemiallogeneic with respect to its mother, and the maternal immune response is a key factor in determining pregnancy outcome. The increased risk of pre-eclampsia in first pregnancies suggests immune system involvement in its pathogenesis. A lengthy period of exposure to paternal semen prior to pregnancy appears to be protective, which may explain in part the three-fold increase in risk of developing pre-eclampsia following use of donor sperm or oocytes. ${ }^{50,51}$

\section{Killer immunoglobulin-like receptors} and the human leucocyte antigen

Expression of major histocompatibility complex molecules by invading extravillous cytotrophoblast cells is limited to the invariant Class $1 \mathrm{~b}$ molecules, human leucocyte antigen (HLA)-E, HLA-F, and HLA-G, and the moderately polymorphic Class Ia antigen HLA-C. Interactions between trophoblast HLA-C and maternal killer-cell immunoglobulin-like receptors (KIR) expressed by uterine natural killer cells are important for regulating trophoblast invasion and are crucial for successful placentation..$^{52}$ The two basic KIR haplotypes, $\mathrm{A}$ and $\mathrm{B}$, differ in that the $\mathrm{B}$ haplotype is more potent in activating uterine natural killer cells, and stimulating the secretion of cytokines essential for trophoblast invasion. Fetal HLA-C antigens are also represented by two groups, HLA-C1 and HLA-C2, which have differing affinities for KIR haplotypes. There is evidence that certain maternal KIR/ fetal HLA-C combinations increase the risk of inefficient placentation leading to pre-eclampsia. ${ }^{53}$

\section{TNF $\alpha$}

Excessive release of tumor necrosis factor alpha (TNF $\alpha)$ is associated with endothelial activation, and plasma levels of TNF $\alpha$ are significantly higher in women with pre-eclampsia. ${ }^{54}$ Furthermore, treatment of pregnant rats with TNF $\alpha$ induces hypertension. ${ }^{55} \mathrm{TNF} \alpha$ is also involved in the production of ROS and oxidant-mediated endothelial damage. The most frequently studied polymorphism in the TNF $\alpha$ gene is the $308 \mathrm{G}>\mathrm{A}$ transition in the promoter region, which is associated with increased production of TNF $\alpha$. This variant has been associated with an increased risk of pre-eclampsia and pre-eclampsia linked disorders, including type 2 diabetes, coronary artery disease, and dyslipidemia. ${ }^{56,57}$ However, a large-scale meta-analysis of this polymorphism failed to demonstrate significant association with pre-eclampsia. ${ }^{58}$

\section{Interleukin I0 (IL-I0)}

Trophoblast invasion and spiral artery remodeling are also regulated by IL- $10^{59}$ which is expressed at lower levels in pre-eclamptic placentae compared to matched controls. ${ }^{60}$ Large-scale studies examining genetic variants of $I L-10$ have failed to demonstrate a significant association with pre-eclampsia. ${ }^{61,62}$

\section{Animal models of pre-eclampsia}

Due to the differences in placental development between humans and other mammals, specifically deep trophoblast invasion, animal models have been of only limited significance in the help to elucidate factors involved in the pathophysiology of pre-eclampsia. ${ }^{63}$ However, recently the murine catechol-O-methyltransferase (COMT) knockout model has been useful in unraveling the significance of 
decreased placental COMT expression in pre-eclampsia. Estradiol is metabolized by cytochrome P450 generating 17-hydroxyestradiol which is a substrate for COMT, which converts 17-hydroxyestradiol into 2-methoxyestradiol (2-ME). 2-ME inhibits HIF- $1 \alpha$ by possibly destabilizing microtubules in trophoblasts. ${ }^{64}$ During pregnancy the concentration of maternal circulatory 2-ME immediately increases and peaks at term. ${ }^{64,65}$ The plasma concentration of 2-ME is decreased in pre-eclampsia. ${ }^{64} \mathrm{COMT}$-deficient mice $\left(\mathrm{COMT}^{-/-}\right)$display a pre-eclampsia-like phenotype, including pregnancy-induced hypertension with proteinuria. ${ }^{64}$ Administration of exogenous 2-ME ameliorates the hypertension, proteinuria, placental defects, acute atherosis, and glomerular and placental endothelial damage present in pregnant $\mathrm{COMT}^{-/-}$mice. It is thought that the pre-eclampsia like symptoms present in $\mathrm{COMT}^{-/}$mice is due to placental accumulation of HIF-1 $\alpha$. In the presence of COMT, 2-ME suppresses HIF- $1 \alpha$ accumulation and production of sFLT1. In $\mathrm{COMT}^{-/-}$mice, however, HIF-1 $\alpha$ accumulation is associated with an increased inflammatory response and endothelial damage.

The rs4680 polymorphism in the coding sequence of COMT produces a $\mathrm{G}$ to A nucleotide substitution leading to a valine to methionine amino acid substitution at amino acid position $158 .{ }^{66}$ The $C O M T^{\text {Met158 }}$ variant has a lower stability and shows a lower enzymatic activity, with this variant present in around $30 \%$ of the population. This polymorphism has been found to be associated with fetal growth restriction and abnormalities. ${ }^{66}$ Pre-eclampsia may therefore be associated with such polymorphisms within the COMT gene, however, robust genetic studies are still needed to confirm or dispute such an association.

\section{Genome-wide screening}

Genome-wide screening provides an unbiased approach to the search for susceptibility genes for pre-eclampsia, unlimited by current understanding of the underlying pathophysiological changes. It therefore offers an opportunity to elucidate previously unsuspected pathogenic pathways, and identify novel interventional targets.

\section{Genome-wide linkage screens (GWLS)}

GWLS have been very successful in identifying highly penetrant variants in monogenic disorders, but this method is inadequately powered for detecting the causal variants with small effect size typical of complex genetic disorders. A number of GWLS have been performed in pre-eclampsia, assessing the segregation of microsatellite alleles in affected siblings. This method can only identify relatively large regions of the genome, typically tens of centimorgan in size, and containing hundreds of genes, many of which may be biologically plausible. Significant linkage with pre-eclampsia on chromosomes $2 \mathrm{p} 13,{ }^{67} 2 \mathrm{p} 25,{ }^{68}$ and $9 \mathrm{p} 13^{68}$ has been reported. Suggestive linkage has also been described at different loci on chromosomes 2q, 9p, 10q, 11q, and 22q. ${ }^{69,70}$ Disappointingly, none of these loci have been independently replicated in another GWLS. Limited statistical power is a major factor in the failure to replicate these GWLS in studies of complex genetic disorders. Meta-analysis of the five GWLS performed in pre-eclampsia produced modest evidence for linkage at several loci, but cautioned that insufficient data were available for conclusive results. ${ }^{71}$

\section{Positional candidate genes}

Activin A receptor type IIA (ACVR2A) has been identified as a strong positional candidate on the 2q22-23 locus. As a key receptor for the cell-signaling protein activin $\mathrm{A}$, an important regulator of human pregnancy, $A C V R 2 A$ represents a biologically plausible candidate. Activin A has also been investigated as a potential biomarker for pre-eclampsia as circulating levels are increased in pre-eclamptic pregnancies. ${ }^{72}$ In a large study of over 1100 pre-eclamptic women and 2200 normotensive controls, four single nucleotide polymorphisms (SNPs) in $A C V R 2 A$ were significantly associated with pre-eclampsia, ${ }^{73}$ and the influence of these variants on the expression and function of ACVR2A is currently being investigated. However, in a study of 74 affected families from Australia/New Zealand the $A C V R 2 A$ association was not replicated. ${ }^{74}$ This gene still remains an interesting target due to its strong biological involvement in the establishment and maintenance of pregnancy.

Within the pre-eclampsia linkage peak on chromosome 2 p25 lies the ROCK 2 gene. This gene encodes rho-associated coiled-coil protein kinase 2 and, interestingly, has been implicated in essential hypertension. ${ }^{68}$ ROCK2 is widely expressed in smooth muscle cells and animal models have indicated a role in vasoconstriction. ${ }^{75,76}$ It has also been shown that syncytiotrophoblast cells of the placenta express ROCK2 and expression is up regulated in pre-eclampsia. ${ }^{77}$ A study examining ten polymorphisms within $R O C K 2$ failed to detect any association with pre-eclampsia. ${ }^{78}$ This study was powered only to detect a genetic effect of 1.6, and a larger study is warranted to investigate both $R O C K 2$ and other genes at the 2 p25 locus. 


\section{Genome-wide association screening (GWAS)}

GWAS is a second unbiased approach to the identification of susceptibility genes for pre-eclampsia. Rather than sequencing the entire genome GWAS makes use of the abundant SNPs scattered throughout the human genome. Due to the lack of independence between the alleles of SNPs in close proximity, a phenomenon known as linkage disequilibrium, a number of representative tagSNPs can be used to infer the genotype of adjacent SNPs. Genotyping of between 300,000 and 1 million carefully selected tagSNPs enables the majority of variation in the human genome to be captured. A SNP that is associated with disease may be causal, or may be acting as a marker for another functional SNP in linkage disequilibrium. Deep resequencing is often required to identify all the polymorphisms present at the susceptibility locus.

GWAS has identified over 2000 genetic variants associated with common diseases, including essential hypertension, coronary artery disease, and type 2 diabetes ${ }^{79}$ conditions which carry an increased risk of pre-eclampsia. Although many of these loci have been independently confirmed, further functional studies are frequently required in order to elucidate the exact pathophysiological mechanisms involved in these disease processes. GWAS to identify susceptibility genes for pre-eclampsia are currently underway; the results are eagerly awaited.

\section{Treatment and prevention of pre-eclampsia}

Prevention, early identification, and individualized treatments may become feasible if reliable early biomarkers can be developed. A recent microarray study has found dysregulation of gene expression in early placenta in women 6 months before development of pre-eclampsia, ${ }^{80}$ confirming placental involvement in this disorder, and also offering the prospect of early prediction of those women at highest risk. It is hoped that completion of GWAS studies and subsequent deep resequencing will help suggest additional biomarkers and improve our understanding of the pathophysiological changes that occur in this disorder.

A number of interventions are available to help treat and prevent pre-eclampsia, including antiplatelet agents, beta blockers, alpha blockers, diuretics, vasodilators (NO agents), and calcium channel blockers. ${ }^{81}$

\section{The benefits of pharmacogenomics}

The aim of pharmacogenomics is to individualize treatments in a rational and directed manner, thereby removing the element of trial and error from current clinical practice. This will in turn reduce morbidity and mortality at the same time as maximizing the benefit to patients and significantly reducing costs. In the UK, around $6.5 \%$ of hospitalizations are due to adverse drug reactions. ${ }^{82}$ The benefits of personalization and rationalization of treatment by pharmacogenomic approaches are therefore clear. They would be of particular benefit for treatment of pre-eclampsia, a condition in which patients can deteriorate rapidly and therefore need treatments that are immediately effective.

Oncology is the current leading example for personalized medicine with pharmacogenomics being used to identify new targets influencing drug absorption, distribution, metabolism and excretion, drug safety, and drug efficacy. The ability to segregate patients into drug responders and nonresponders is the cornerstone of personalized medicine and is now becoming standard practice in the use of oncology medication. Genetic prediction of adverse effects is one of the major successes of pharmacogenomics, for example, prediction of hypersensitivity to the antiretroviral drug abacavir used to treat patients infected with human immunodeficiency virus. ${ }^{83,84}$

A clear message coming from researchers interested in pharmacogenomics and personalized medicine is that translation of this research into clinical benefit demands access to large, well-characterized sample bio banks. This will require large-scale international collaborations, exemplified by the International Warfarin Pharmacogenetics Consortium which has identified a model comprising environmental factors (age, height, weight, and amiodarone use) and genotype at rs9923231 (VKORC1), rs1799853 and rs 1057910 (CYP2C9*2 and *3), rs2108622 (CYP4F2), and rs6042 (F7), which accounts for over $50 \%$ of warfarin stable dose variance. ${ }^{85}$ Sharing of knowledge has been facilitated by the development of databases, such as the Pharmacogenomics Knowledge Base (PharmGkb), ${ }^{86}$ to act as worldwide resources.

The ever-increasing level of data being generated about our genomes and health and disease is leading the way for socalled proactive $\mathrm{P} 4$ (prediction, personalization, prevention, participation) medicine. P4 medicine is important for future health as it will enable the prediction of individual health risk and also allow the development of personalized treatment based on an individual's genetic variation. Furthermore, P4 medicine will lead to the prevention of more disease by the design of new therapeutic drugs. However, for P4 medicine to be fully beneficial patients, doctors and the medical community must all understand and participate ${ }^{87}$ 


\section{Drug metabolism is the key to pharmacogenomics}

The challenge within pharmacogenomics is to define the physiological pathways that are involved in drug metabolism; pathways which involve multiple interacting proteins. Each of these proteins may contain a polymorphism, transcription of these proteins is in turn regulated by proteins, which again may contain polymorphisms in their genetic coding. Further complexity is added as these biochemical pathways can interact amongst themselves in complex ways which are as yet undefined. This can make determining the actual cause of a change to a response to a drug very difficult. Such complexity has led to two generic streams for pharmacogenomic research: studies based on the pathophysiological pathways involved in disease and studies based on genomewide association screening.

\section{Nitric oxide synthase as a potential target for therapy for pre-eclampsia}

Endothelial dysfunction is characteristic of pre-eclampsia, being associated with the hypertension and proteinuria that are symptomatic of this disorder. Among several mediators released by the endothelium, NO plays an important role in regulating endothelial function (see Figure 1). NO produced by the endothelium targets the vascular smooth muscle, and activates soluble guanylate cyclase by interacting with its heme group. This enzyme synthesizes cyclic guanosine monophosphate from guanosine triphosphate, leading to an accumulation of cyclic guanosine monophosphate. This activates intracellular signaling pathways that decrease the degree of vascular smooth muscle contraction leading to vessel relaxation. ${ }^{88}$ In addition to functioning as an endogenous vasodilator, NO also serves as a platelet inhibitor, antioxidant, and regulator of vascular endothelium by sustaining its anticoagulant and antithrombogenic properties, ${ }^{89}$ all of which are perturbed in pre-eclampsia. Within the cardiovascular system it is the endothelial isoform of nitric oxide synthase (eNOS) which is responsible for NO synthesis. ${ }^{90}$ Reduced expression of eNOS consequently results in reduced NO bioavailability which plays a significant role in the endothelial dysfunction associated with pre-eclampsia. ${ }^{91}$ eNOS represents an interesting pharmacogenomic target, but the multiple interdependent control mechanisms and signaling pathways that act throughout the various stages of the enzyme's life history make this a difficult challenge.

Pre-eclampsia is also associated with an increase in oxidative stress. The ROS superoxide anion is able to react with NO resulting in the formation of the highly damaging peroxynitrite, and further reducing the bioavailability of NO. ${ }^{92}$ ROS can also cause oxidation of the tetrahydrobiopterin cofactor of eNOS, resulting in uncoupling of this enzyme and further production of superoxide anion in favor of $\mathrm{NO},{ }^{93}$ a vicious cycle that further increases oxidative stress.

The $e N O S$ gene, located on 7q35-7q36, is approximately 21 to $22 \mathrm{~Kb}$ and consists of 26 exons and 25 introns. ${ }^{94,95}$ Since its characterization in the 1990s, a large number of polymorphic sites have been identified in the eNOS gene, including variable number tandem repeats, dinucleotide repeats $(\mathrm{CA}) n$, and SNPs. Several polymorphisms have been associated with pre-eclampsia and other cardiovascular

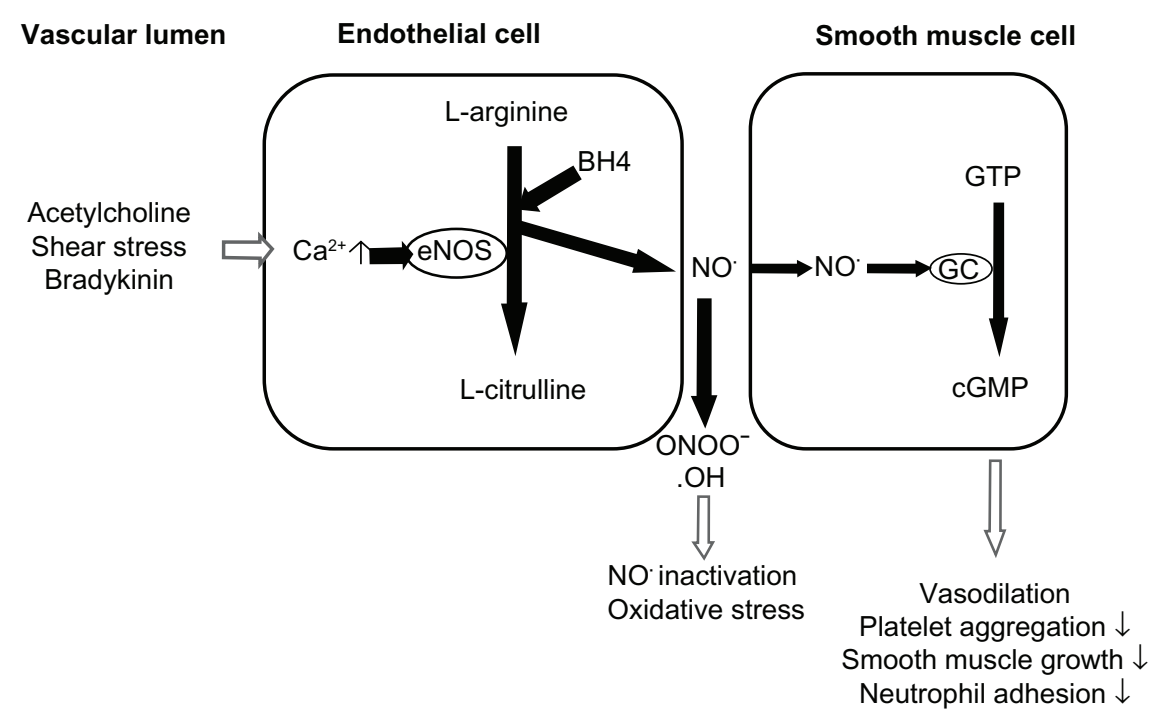

Figure I The importance of nitric oxide (NO) in the regulation of endothelial function.

Abbreviations: eNOS, endothelial nitric oxide synthase; BH4, tetrahydrobiopterin; GC, guanylate cyclase; GTP, guanosine triphosphate; cGMP, cyclic guanosine monophosphate; $\mathrm{ONOO}^{-}$, peroxynitrite; $\mathrm{OH}$, hydroxide. 
and hypertensive disorders. ${ }^{96-98}$ A relationship between eNOS polymorphisms and differential responses to several classes of cardiovascular drugs has been shown, ${ }^{99}$ some of which are used for the treatment of pre-eclampsia.

In animal models statins have been shown to be beneficial in ameliorating pre-eclampsia ${ }^{100}$ and currently the StAmP (Trial of provaStatin to Ameliorate early onset Pre-eclampsia) trial is underway to assess the use of statins in pregnancy as a therapeutic intervention to prolong pre-eclamptic pregnancies, thereby reducing the incidence of prematurity associated with the disorder. ${ }^{101}$ Recent evidence suggests genetic polymorphisms of eNOS modulate the effects of statins. Statin treatment induced a greater increase in eNOS mRNA levels in cultured endothelial cells with the CC genotype at the $-786 \mathrm{~T}>\mathrm{C}$ polymorphism compared to cells with the TT genotype. ${ }^{102}$ These findings have been confirmed in a clinical study showing that atorvastatin increases the bioavailability of NO and decreases oxidative stress in CC homozygotes. ${ }^{103}$ The same polymorphism in the eNOS gene modulates the anti-inflammatory effect of atorvastatin, resulting in significant reductions in the inflammatory cytokines CD40L, VCAM-1, P-Selectin, and MMP-9 in individuals with the CC genotype but not the TT genotype. ${ }^{104}$ These findings suggest that statins might be more useful for the treatment of pre-eclampsia in women with the CC genotype than in those with the TT genotype.

A further polymorphism in intron $4(4 \mathrm{a} / \mathrm{b})$ of the eNOS gene is also associated with modulation of the response to statins. In a study evaluating coronary vasodilatation induced by adenosine after 6-months' treatment with pravastatin, individuals carrying an A allele showed significant improvement of vasodilatation compared to homozygous bb individuals, possibly due to increased endothelial production of NO. ${ }^{105}$

\section{Prevention of pre-eclampsia Labetalol}

Labetalol is a mixed alpha- and beta-blocker that is used for controlling high blood pressure during pregnancy. Although no studies have been performed examining pharmacogenomic effects on labetalol, a number of studies have been performed assessing other beta-blockers in patients with hypertension which may be of relevance to the use of labetalol in pre-eclampsia. Using a technique similar to GWAS, polymorphisms in eNOS have been shown to be associated with variations in pharmacological responses to the beta-blocker atenolol. In hypertensive patients, allele $\mathrm{G}$ of the A2996G polymorphism in eNOS is associated with a greater decrease in blood pressure following treatment with atenolol compared with patients with the A allele. ${ }^{106}$ Allele A of the G498A polymorphism in the eNOS gene is also associated with a better response to atenolol treatment. ${ }^{106}$ The presence of a $2996 \mathrm{G}$ allele and a 498A allele may therefore be beneficial for patients treated with beta-blockers. These promising results need to be confirmed in a higher number of patients from different populations but may be important when considering pharmacogenomic approaches to the treatment of pre-eclampsia.

\section{Hydralazine (HDZ)}

HDZ is commonly used in pre-eclampsia as an intravenous treatment for quickly lowering severely high blood pressure during pregnancy. ${ }^{107}$ Hypotension is a frequent adverse effect of HDZ treatment. ${ }^{107} \mathrm{HDZ}$ is biotransformed by the enzyme N-acetyltransferase (NAT) forming acetyl HDA, which spontaneously converts to the stable product 3-met hyl-S-triazolo-[3,4-a]-phthalazine. ${ }^{108}$ Two isoforms of $N A T$ are encoded by $N A T 1$ and $N A T 2$. Several polymorphisms in NAT1 and NAT2 have functional consequences including truncation of the proteins, which leads to reduced enzyme activity. This affects the rates of inactivation of many drugs, including HDZ. ${ }^{109}$

As previously mentioned, COMT deficiency is implicated in the pathogenesis of pre-eclampsia. Importantly, HDZ has also been shown to inhibit placental COMT activity. ${ }^{110}$ Therefore, HDZ mediated suppression of COMT/2-ME needs to be carefully evaluated for its connection with possible drug-exacerbated pre-eclampsia.

However, it is questionable whether pretreatment $N A T$ genotyping would be clinically justified, as the benefits of HDZ therapy in severe pre-eclampsia outweigh the risk of adverse drug reactions.

\section{Aspirin}

Aspirin reduces the risk of pre-eclampsia ${ }^{111}$ through its antithrombotic action. A recent Cochrane review showed that aspirin at doses of between 50 and $150 \mathrm{mg} /$ day reduces the risk of pre-eclampsia by $17 \%$ (relative risk $0.83 ; 95 \%$ confidence interval 0.77-0.89). ${ }^{112}$ Current guidelines from the National Institute for Health and Clinical Excellence ${ }^{81}$ recommend that women at high risk of pre-eclampsia should take aspirin $75 \mathrm{mg}$ daily from 12 weeks of pregnancy until the birth of the baby. Low-dose aspirin functions as an antiplatelet agent through its ability to irreversibly acetylate and thus inhibit the enzyme cyclo-oxygenase-1 (COX-1). This suppresses the synthesis of thromboxane $A_{2}$, a potent 
vasoconstrictor and activator of platelet aggregation. ${ }^{112}$ Therefore, low-dose aspirin may enhance uterine blood flow and tissue perfusion, and promote optimal uterine hemodynamics.

There is interindividual variation in the antiplatelet effects of aspirin giving rise to the concept of antiplatelet drug resistance. ${ }^{113}$ A number of laboratory assays are available to test for aspirin resistance which include light transmission aggregometry, platelet function analyser-100, VerifyNow ${ }^{\circledR}$ Aspirin system (Accumetrics, San Diego, CA), thromboelastography, or measurements of serum levels of thromboxane $\mathrm{B}_{2}$ or the urinary metabolite 11-dehydro-thromboxane $\mathrm{B}_{2}$. The definition of antiplatelet drug resistance is controversial and therefore the reported prevalence varies widely, between 5\% and $60 \%$, depending on the laboratory methods used and the population studied. ${ }^{114-116}$ However, it is important to note that poor compliance by patients has been identified as a primary cause of resistance. ${ }^{117}$ In addition to COX-1-specific effects, aspirin also has COX-1 independent effects, which may be subject to more interindividual variability and may explain the adverse outcomes among patients with high platelet reactivity. ${ }^{114,118}$

A number of mechanisms may be related to aspirin resistance. ${ }^{119}$ Clinical factors including poor patient compliance, drug-absorption abnormalities, or drug-drug interactions play a role. ${ }^{120}$ Cellular factors have also been proposed to influence aspirin efficacy, such as inadequate suppression of platelet COX-1 due to increased platelet turnover, over expression of COX-2 mRNA, erythrocyte-platelet interaction, catecholamine levels, or the generation of 8-iso- $\mathrm{PGF}_{2}{ }^{121}$ Polymorphisms in both the $C O X-1$ and $C O X-2$ genes may have roles in aspirin resistance. ${ }^{122}$ The $C O X-1$ C50T and COX-2 (G-765C) polymorphisms have both been associated with the efficiency of reduction of thromboxane $\mathrm{B}_{2}$ levels after aspirin treatment. ${ }^{118,123}$
A number of polymorphisms have been identified as being associated with aspirin drug resistance (see Table 3). ${ }^{121,124}$ However, these studies have often been underpowered and inconclusive. This is perhaps not surprising given the different methods used to assess resistance and the lack of assessment of compliance. A comprehensive systematic review and meta-analysis of pharmacogenomics of aspirin resistance has been performed identifying 50 polymorphisms in eleven genes in the aspirin pathway. ${ }^{125}$ A subgroup analysis in healthy individuals identified a statistically significant genetic association between aspirin resistance and a polymorphism in the glycoprotein (GP) IIb/ IIIa platelet receptor gene. The platelet GPIIb/IIIa receptor is essential for platelet activation and aggregation by binding fibrinogen and von Willebrand factor. This receptor complex is the main pharmaceutical target for aspirin and other antiplatelet therapies. The GP IIb/IIIa complex is highly polymorphic. Healthy carriers of the $\mathrm{PI}^{\mathrm{A} 2}$ allele, which is responsible for a Pro33 Leu amino acid change, are 2.36 times more likely to display resistance to aspirin ${ }^{126}$ and therefore require a greater dose of aspirin to experience the same antiaggregant effect as do subjects with a $\mathrm{PI}^{\mathrm{A} 1}$ homozygous genotype. ${ }^{127}$ However, no studies have been undertaken in pregnant women on aspirin to determine whether there is genetic variability in response to aspirin, and certainly this has never been related to clinical outcomes.

A second complex which may also regulate patient response to aspirin and other antiplatelet agents is the GP Ia/IIa complex, a high-affinity receptor for collagen which plays a key role in platelet adhesion. Polymorphisms that alter the structure and density of the GP Ia/IIa receptor complex on the platelet surface include C807T (Phe 224), a silent polymorphism affecting the Ia subunit. The $807 \mathrm{~T}$ allele is associated with up to ten times higher expression of the receptor on the platelet surface and may modify the effect of antiplatelet drugs. ${ }^{128}$

Table 3 Summary of pharmacogenomic studies on antiplatelet agents

\begin{tabular}{|c|c|c|c|c|}
\hline Protein & Polymorphism & $\begin{array}{l}\text { Patient numbers } \\
\text { studied }\end{array}$ & Functional effects & Clinical effects \\
\hline GP Ilb/llla & $\mathrm{Pl}^{\mathrm{A}}$ (Pro33Leu) & $>5000$ & $\begin{array}{l}\text { Individuals with } \mathrm{P}^{\mathrm{A} 2} \text { allele require higher dose of aspirin } \\
\text { to achieve comparable anti-aggregant effect as wild-type } \\
\text { homozygotes }\end{array}$ & $\begin{array}{l}\text { Increased risk of } \\
\text { thrombosis }\end{array}$ \\
\hline GPla & C807T & 1170 & $\begin{array}{l}\text { Associated with collagen-receptor density on the platelet } \\
\text { membrane surface and greater platelet reactivity }\end{array}$ & Conflicting data \\
\hline COX-I & C50T & 563 & Associated with higher levels of thromboxane $B_{2}$ & No clinical data \\
\hline COX-2 & G-765C & 24 & $\begin{array}{l}\text { Associated with a higher reduction of thromboxane } \\
B_{2} \text { levels after aspirin treatment }\end{array}$ & No clinical data \\
\hline ADP subtype receptor & $\mathrm{P} \mathrm{Y}_{12}$ & 980 & $\begin{array}{l}\text { Associated with reduced platelet aggregation after } \\
\text { aspirin intake }\end{array}$ & No clinical data \\
\hline
\end{tabular}

Abbreviations: ADP, adenosine diphosphate; COX, cyclooxygenase; GP, glycoprotein. 


\section{Magnesium sulfate}

Magnesium sulfate is used therapeutically to prevent eclamptic convulsions in women with pre-eclampsia. The pharmacological actions of magnesium include cerebral vasodilatation thereby reducing cerebral ischemia, ${ }^{129}$ or blocking of neuronal damage associated with ischemia. ${ }^{130}$ However, magnesium sulfate also has side effects for the mother. ${ }^{131}$ An increase in postpartum hemorrhage has been reported following magnesium sulfate treatment, ${ }^{132}$ although its incidence was not increased in the Magpie trial. ${ }^{133}$ Importantly, magnesium is able to cross the placenta and hypermagnesemia in the neonate is associated with flaccidity, hyporeflexia, and respiratory depression. ${ }^{134}$ To the best of the authors' knowledge, no pharmacogenomic studies have been performed with magnesium sulfate.

\section{Calcium channel blockers}

The calcium channel blockers nifedpine, verapamil, and nicardipine are also recommended to treat hypertension in pre-eclampsia. ${ }^{135}$ Calcium channel blockers function by blocking voltage-gated calcium channels in the heart and vasculature, thereby reducing intracellular calcium. In the heart, this results in decreased cardiac contractility and reduced cardiac output; in the blood vessels, this leads to decreased smooth muscle contraction and peripheral resistance. Although no pharmacogenomic studies have been performed in pre-eclampsia, over recent years, a number of studies have examined calcium channel blockers in the treatment of hypertension. Three SNPs in CACNA1A (rs2239050, rs2238032, and rs2239128) have been associated with success of treatment in a study of blood pressure lowering with calcium channel blockers, ${ }^{136}$ however, Beitelshees et $\mathrm{al}^{137}$ failed to replicate this finding. A recent study has also shown that individuals with rs $1051375 \mathrm{~A} / \mathrm{A}$ benefit from treatment with a calcium channel blocker, whereas those with the $\mathrm{G} / \mathrm{G}$ genotype would benefit from treatment with a beta blocker, and in those individuals that are heterozygous it does not matter which treatment is chosen. ${ }^{137}$ Suggestive associations between CYP3A $5 * 3$ and CYP 3 A $5 * 6$ variants and verapamil treatment for blood pressure and hypertension risk outcomes in black and Hispanic populations have also been observed. ${ }^{138}$ The Glu65 Lys and Val110Leu variants of $K C N M B 1$ have also been studied with regard to systolic blood pressure regulation by verapamil. Although blood pressure response did not vary by genotype, Lys65 carriers achieved earlier blood pressure control and required fewer additional treatments. Leu110 carriers were found to have a reduced risk of death, myocardial infarction, or stroke. ${ }^{139}$
Higher mortality rates have also been reported for individuals with the Ser49-Arg389 variant of $A D R B 1$ following treatment with verapamil. ${ }^{140}$ Additionally, individuals homozygous for the $\mathrm{T}$ allele of NPPA T2238C had more favorable clinical outcomes when treated with a calcium channel blocker whereas $\mathrm{C}$ carriers responded better to a diuretic. ${ }^{141}$

\section{Conclusion}

The need for collaboration within the field of genetics of preeclampsia, as with all other complex genetic disorders, is now accepted by researchers. Only large-scale collaborations can achieve sufficient sample sizes to perform adequately powered studies. Whilst a role for pharmacogenomics is accepted in the field of cancer treatment, further research is needed before pharmacogenomic approaches can be considered appropriate for pre-eclampsia. Due to concerns about possible teratogenic/ harmful effects on the fetus only minimal medication is given to a woman during pregnancy. A recent Confidential Enquiry into Maternal and Child Health report, attributes the occurrence of fatal intracranial hemorrhages to inadequate treatment of severe systolic hypertension $(>160 \mathrm{mmHg})$ in women with pre-eclampsia, recommending urgent and effective treatment for such cases. ${ }^{142}$ Pharmacogenomics could help reduce the incidence of such fatal hemorrhages by helping to ensure that women received the optimal treatment regimen for them. Such accurate prediction of which women will respond well to a particular treatment will be further beneficial in the management of pre-eclampsia by preventing unnecessary exposure of the fetus to ineffective drugs. Progress in understanding the genetic component of pre-eclampsia will aid development of novel pharmaceutical treatments; personalized medicine informed by pharmacogenomics will target the treatments for this devastating disorder of pregnancy at those most likely to benefit.

\section{Disclosure}

The authors report no conflicts of interest in this work.

\section{References}

1. Redman CW. Preeclampsia: a multi-stress disorder. Rev Med Interne. 2011;32 Suppl 1:S41-S44.

2. Villar K, Say L, Gulmezoglu AM, et al. Eclampsia and pre-eclampsia: a health problem for 2,000 years. In: Critchley H, MacLean AB, Poston L, Walker JJ, editors. Preeclampsia. London: RCOG Press; 2003:189-207.

3. Kajantie E, Eriksson JG, Osmond C, Thornburg K, Barker DJ. Pre-eclampsia is associated with increased risk of stroke in the adult offspring: the Helsinki birth cohort study. Stroke. 2009;40(4):1176-1180.

4. Bauer ST, Cleary KL. Cardiopulmonary complications of pre-eclampsia Semin Perinatol. 2009;33(3):158-165.

5. Zeeman GG. Neurologic complications of pre-eclampsia. Semin Perinatol. 2009;33(3):166-172. 
6. Roberts JM, Hubel CA. The two stage model of preeclampsia: variations on the theme. Placenta. 2009;30 Suppl A:S32-S37.

7. Redman CW, Sargent IL. Placental stress and pre-eclampsia: a revised view. Placenta. 2009;30 Suppl A:S38-S42.

8. Redman CW, Sargent IL. Immunology of pre-eclampsia. Am J Reprod Immunol. 2010;63(6):534-543.

9. Brown MA, Lindheimer MD, de Swiet M, Van Assche A, Moutquin JM. The classification and diagnosis of the hypertensive disorders of pregnancy: statement from the International Society for the Study of Hypertension in Pregnancy (ISSHP). Hypertens Pregnancy. 2001;20(1):IX-XIV.

10. Roberts JM, Redman CW. Pre-eclampsia: more than pregnancy-induced hypertension. Lancet. 1993;341(8858):1447-1451.

11. McCarthy AL, Taylor P, Graves J, Raju SK, Poston L. Endotheliumdependent relaxation of human resistance arteries in pregnancy. Am J Obstet Gynecol. 1994;171(5):1309-1315.

12. Ward K, Lindheimer MD. Genetic factors in the etiology of preeclampsia/eclampsia. In: Lindheimer MD, Roberts JM, Cunningham FD, editors. Chesley's Hypertensive Disorders in Pregnancy. London: Elsevier; 2009:51-72.

13. Cox B, Sharma P, Evangelou AI, et al. Translational analysis of mouse and human placental protein and mRNA reveals distinct molecular pathologies in human preeclampsia. Mol Cell Proteomics. 2011;10(12): M111.012526.

14. Vianna P, Bauer ME, Dornfeld D, Chies JA. Distress conditions during pregnancy may lead to pre-eclampsia by increasing cortisol levels and altering lymphocyte sensitivity to glucocorticoids. Med Hypotheses. 2011;77(2):188-191.

15. Robinson CJ, Alanis MC, Wagner CL, Hollis BW, Johnson DD. Plasma 25-hydroxyvitamin D levels in early-onset severe preeclampsia. Am J Obstet Gynecol. 2010;203(4):366.

16. Cooper DW, Brennecke SP, Wilton AN. Genetics of pre-eclampsia. Hypertens Pregnancy. 1993;12:1-23.

17. Fisher SJ, McMaster M, Roberts JM. The placenta in normal pregancy and preeclampsia. In: Lindheimer MD, Roberts JM, Cunningham FD, editors. Chesley's Hypertensive Disorders in Pregnancy. London: Elsevier; 2009:73-86.

18. Kurdoglu M, Kurdoglu Z, Ozen S, et al. Expression of laminin receptor 1 in human placentas from normal and preeclamptic pregnancies and its relationship with the severity of preeclampsia. J Perinat Med. 2011;39(4):411-416.

19. Skjaerven R, Vatten LJ, Wilcox AJ, Ronning T, Irgens LM, Lie RT. Recurrence of pre-eclampsia across generations: exploring fetal and maternal genetic components in a population based cohort. BMJ. 2005;331(7521):877.

20. Haig D. Genetic conflicts in human pregnancy. Q Rev Biol. 1993;68(4): 495-532.

21. GOPEC Consortium. Disentangling fetal and maternal susceptibility for pre-eclamspia: a British multicenter candidate-gene study. Am J Hum Genet. 2005;77:127-131.

22. Dekker G, Robillard PY, Roberts C. The etiology of preeclampsia: the role of the father. J Reprod Immunol. 2011;89(2):126-132.

23. Ainsworth HF, Unwin J, Jamison DL, Cordell HJ. Investigation of maternal effects, maternal-fetal interactions and parent-of-origin effects (imprinting), using mothers and their offspring. Genet Epidemiol. 2011;35(1):19-45.

24. Mutze S, Rudnik-Schoneborn S, Zerres K, Rath W. Genes and the preeclampsia syndrome. J Perinat Med. 2008;36(1):38-58.

25. de Maat MP, de Groot CJ. Thrombophilia and pre-eclampsia. Semin Thromb Hemost. 2011;37(2):106-110.

26. Isermann B, Sood R, Pawlinski R, et al. The thrombomodulin-protein C system is essential for the maintenance of pregnancy. Nat Med.2003; 9(3):331-337.

27. Dalmaz CA, Santos KG, Botton MR, Tedoldi CL, Roisenberg I. Relationship between polymorphisms in thrombophilic genes and preeclampsia in a Brazilian population. Blood Cells Mol Dis. 2006;37(2): $107-110$.
28. Gerhardt A, Goecke TW, Beckmann MW, et al. The G20210A prothrombin-gene mutation and the plasminogen activator inhibitor (PAI-1) 5G/5G genotype are associated with early onset of severe preeclampsia. J Thromb Haemost. 2005;3(4):686-691.

29. Lin J, August P. Genetic thrombophilias and preeclampsia: a metaanalysis. Obstet Gynecol. 2005;105(1):182-192.

30. Rodger MA, Betancourt MT, Clark P, et al. The association of factor V leiden and prothrombin gene mutation and placenta-mediated pregnancy complications: a systematic review and meta-analysis of prospective cohort studies. PLoS Med. 2010;7(6):e1000292.

31. Medica I, Kastrin A, Peterlin B. Genetic polymorphisms in vasoactive genes and preeclampsia: a meta-analysis. Eur J Obstet Gynecol Reprod Biol. 2007;131(2):115-126.

32. Zafarmand MH, Nijdam ME, Franx A, Grobbee DE, Bots ML. The angiotensinogen gene M235T polymorphism and development of preeclampsia/eclampsia: a meta-analysis and meta-regression of observational studies. J Hypertens. 2008;26(9):1726-1734.

33. Brennecke SP, Gude NM, Di Iulio JL, King RG. Reduction of placental nitric oxide synthase activity in pre-eclampsia. Clin Sci (Lond). 1997;93(1):51-55.

34. Papazoglou D, Galazios G, Koukourakis MI, et al. Vascular endothelial growth factor gene polymorphisms and pre-eclampsia. Mol Hum Reprod. 2004;10(5):321-324.

35. Bower C, Stanley F, Walters BN. Pre-eclampsia and trisomy 13. Lancet. 1987;2(8566):1032.

36. Chen CP. Placental abnormalities and preeclampsia in trisomy 13 pregnancies. Taiwan J Obstet Gynecol. 2009;48(1):3-8.

37. Burton GJ, Jauniaux E. Oxidative stress. Best Pract Res Clin Obstet Gynaecol. 2011;25(3):287-299.

38. Jauniaux E, Poston L, Burton GJ. Placental-related diseases of pregnancy: Involvement of oxidative stress and implications in human evolution. Hum Reprod Update. 2006;12(6):747-755.

39. Foidart JM, Hustin J, Dubois M, Schaaps JP. The human placenta becomes haemochorial at the 13th week of pregnancy. Int J Dev Biol. 1992;36(3):451-453.

40. Walker JJ. Antioxidants and inflammatory cell response in preeclampsia. Semin Reprod Endocrinol. 1998;16(1):47-55.

41. Mistry HD, Kurlak LO, Williams PJ, Ramsay MM, Symonds ME, Pipkin FB. Differential expression and distribution of placental glutathione peroxidases 1, 3 and 4 in normal and preeclamptic pregnancy. Placenta. 2010;31(5):401-408.

42. Wickens D, Wilkins MH, Lunec J, Ball G, Dormandy TL. Free radical oxidation (peroxidation) products in plasma in normal and abnormal pregnancy. Ann Clin Biochem. 1981;18(Pt 3):158-162.

43. Canto P, Canto-Cetina T, Juarez-Velazquez R, et al. Methylenetetrahydrofolate reductase C677T and glutathione S-transferase P1 A313G are associated with a reduced risk of preeclampsia in Maya-Mestizo women. Hypertens Res. 2008;31(5):1015-1019.

44. Gebhardt GS, Peters WH, Hillermann R, et al. Maternal and fetal single nucleotide polymorphisms in the epoxide hydrolase and gluthatione S-transferase P1 genes are not associated with pre-eclampsia in the Coloured population of the Western Cape, South Africa. J Obstet Gynaecol. 2004;24(8):866-872.

45. Laasanen J, Romppanen EL, Hiltunen M, et al. Two exonic single nucleotide polymorphisms in the microsomal epoxide hydrolase gene are jointly associated with preeclampsia. Eur J Hum Genet. 2002;10(9):569-573.

46. Descamps OS, Bruniaux M, Guilmot PF, Tonglet R, Heller FR. Lipoprotein metabolism of pregnant women is associated with both their genetic polymorphisms and those of their newborn children. J Lipid Res. 2005;46(11):2405-2414.

47. Kim YJ, Williamson RA, Chen K, Smith JL, Murray JC, Merrill DC. Lipoprotein lipase gene mutations and the genetic susceptibility of preeclampsia. Hypertension. 2001;38(5):992-996.

48. Atkinson KR, Blumenstein M, Black MA, et al. An altered pattern of circulating apolipoprotein E3 isoforms is implicated in preeclampsia. J Lipid Res. 2009;50(1):71-80. 
49. Zhang C, Austin MA, Edwards KL, et al. Functional variants of the lipoprotein lipase gene and the risk of preeclampsia among nonHispanic Caucasian women. Clin Genet. 2006;69(1):33-39.

50. Wang JX, Knottnerus AM, Schuit G, Norman RJ, Chan A, Dekker GA. Surgically obtained sperm, and risk of gestational hypertension and pre-eclampsia. Lancet. 2002;359(9307):673-674.

51. Klatsky PC, Delaney SS, Caughey AB, Tran ND, Schattman GL, Rosenwaks $\mathrm{Z}$. The role of embryonic origin in preeclampsia: a comparison of autologous in vitro fertilization and ovum donor pregnancies. Obstet Gynecol. 2010;116(6):1387-1392.

52. Bulmer JN, Williams PJ, Lash GE. Immune cells in the placental bed. Int J Dev Biol. 2010;54(2-3):281-294.

53. Hiby SE, Walker JJ, O'Shaughnessy KM, et al. Combinations of maternal KIR and fetal HLA-C genes influence the risk of preeclampsia and reproductive success. J Exp Med. 2004;200(8):957-965.

54. Sharma A, Satyam A, Sharma JB. Leptin, IL-10 and inflammatory markers (TNF-alpha, IL-6 and IL-8) in pre-eclamptic, normotensive pregnant and healthy non-pregnant women. Am J Reprod Immunol. 2007;58(1):21-30.

55. Alexander BT, Cockrell KL, Massey MB, Bennett WA, Granger JP. Tumor necrosis factor-alpha-induced hypertension in pregnant rats results in decreased renal neuronal nitric oxide synthase expression. Am J Hypertens. 2002;15(2 Pt 1):170-175.

56. Elahi MM, Asotra K, Matata BM, Mastana SS. Tumor necrosis factor alpha -308 gene locus promoter polymorphism: an analysis of association with health and disease. Biochim Biophys Acta. 2009;1792(3): 163-172.

57. Saarela T, Hiltunen M, Helisalmi S, Heinonen S, Laakso M. Tumour necrosis factor-alpha gene haplotype is associated with pre-eclampsia Mol Hum Reprod. 2005;11(6):437-440.

58. Bombell S, McGuire W. Tumour necrosis factor (-308A) polymorphism in pre-eclampsia: meta-analysis of 16 case-control studies. Aust $N Z J$ Obstet Gynaecol. 2008;48(6):547-551.

59. Renaud SJ, Macdonald-Goodfellow SK, Graham CH. Coordinated regulation of human trophoblast invasiveness by macrophages and interleukin 10. Biol Reprod. 2007;76(3):448-454.

60. Makris A, Xu B, Yu B, Thornton C, Hennessy A. Placental deficiency of interleukin-10 (IL-10) in preeclampsia and its relationship to an IL10 promoter polymorphism. Placenta. 2006;27(4-5):445-451.

61. Daher S, Sass N, Oliveira LG, Mattar R. Cytokine genotyping in preeclampsia. Am J Reprod Immunol. 2006;55(2):130-135.

62. Goddard KA, Tromp G, Romero R, et al. Candidate-gene association study of mothers with pre-eclampsia, and their infants, analyzing 775 SNPs in 190 genes. Hum Hered. 2007;63(1):1-16.

63. Carter AM, Pijnenborg R. Evolution of invasive placentation with special reference to non-human primates. Best Pract Res Clin Obstet Gynaecol. 2011;25(3):249-257.

64. Kanasaki K, Palmsten K, Sugimoto H, et al. Deficiency in catecholO-methyltransferase and 2-methoxyoestradiol is associated with pre-eclampsia. Nature. 2008;453(7198):1117-1121.

65. Berg D, Sonsalla R, Kuss E. Concentrations of 2-methoxyoestrogens in human serum measured by a heterologous immunoassay with an 125I-labelled ligand. Acta Endocrinol (Copenh). 1983;103(2): 282-288.

66. Sata F, Yamada H, Suzuki K, et al. Functional maternal catecholO-methyltransferase polymorphism and fetal growth restriction. Pharmacogenet Genomics. 2006;16(11):775-781.

67. Arngrimsson R, Sigurard ttir S, Frigge ML, et al. A genome-wide scan reveals a maternal susceptibility locus for pre-eclampsia on chromosome 2p13. Hum Mol Genet. 1999;8(9):1799-1805.

68. Laivuori H, Lahermo P, Ollikainen V, et al. Susceptibility loci for preeclampsia on chromosomes 2p25 and 9p13 in Finnish families. Am J Hum Genet. 2003;72(1):168-177.

69. Moses EK, Lade JA, Guo G, et al. A genome scan in families from Australia and New Zealand confirms the presence of a maternal susceptibility locus for pre-eclampsia, on chromosome 2. Am J Hum Genet. 2000;67(6):1581-1585.
70. Lachmeijer AM, Arngrimsson R, Bastiaans EJ, et al. A genome-wide scan for preeclampsia in the Netherlands. Eur J Hum Genet. 2001;9(10): 758-764.

71. Zintzaras E, Kitsios G, Harrison GA, et al. Heterogeneity-based genome search meta-analysis for preeclampsia. Hum Genet. 2006;120(3): 360-370.

72. Akolekar R, Etchegaray A, Zhou Y, Maiz N, Nicolaides KH. Maternal serum activin a at 11-13 weeks of gestation in hypertensive disorders of pregnancy. Fetal Diagn Ther. 2009;25(3):320-327.

73. Roten LT, Johnson MP, Forsmo S, et al. Association between the candidate susceptibility gene ACVR2A on chromosome 2 q22 and pre-eclampsia in a large Norwegian population-based study (the HUNT study). Eur J Hum Genet. 2009;17(2):250-257.

74. Fitzpatrick E, Johnson MP, Dyer TD, et al. Genetic association of the activin A receptor gene (ACVR2A) and pre-eclampsia. Mol Hum Reprod. 2009;15(3):195-204.

75. Riento K, Ridley AJ. Rocks: multifunctional kinases in cell behaviour. Nat Rev Mol Cell Biol. 2003;4(6):446-456.

76. Kandabashi T, Shimokawa H, Miyata K, et al. Inhibition of myosin phosphatase by upregulated rho-kinase plays a key role for coronary artery spasm in a porcine model with interleukin-1beta. Circulation. 2000;101(11):1319-1323.

77. Ark M, Yilmaz N, Yazici G, Kubat H, Aktas S. Rho-associated protein kinase II (rock II) expression in normal and preeclamptic human placentas. Placenta. 2005;26(1):81-84.

78. Peterson H, Laivuori H, Kerkela E, et al. ROCK2 allelic variants are not associated with pre-eclampsia susceptibility in the Finnish population. Mol Hum Reprod. 2009;15(7):443-449.

79. Wellcome Trust Case Control Consortium. Genome-wide association study of 14,000 cases of seven common diseases and 3,000 shared controls. Nature. 2007;447(7145):661-678.

80. Founds SA, Conley YP, Lyons-Weiler JF, Jeyabalan A, Hogge WA, Conrad KP. Altered global gene expression in first trimester placentas of women destined to develop preeclampsia. Placenta. 2009; 30(1):15-24.

81. National Institute of Clinical Excellence (NICE). Hypertension in Pregnancy: The Management of Hypertensive Disorders During Pregnancy. NICE Clinical Guideline CG107. London: NICE; 2011. Available from: http://www.nice.org.uk/nicemedia/live/13098/50475/50475.pdf. Accessed January 13, 2012.

82. Pirmohamed M, James S, Meakin S, et al. Adverse drug reactions as cause of admission to hospital: prospective analysis of 18,820 patients. BMJ. 2004;329(7456):15-19.

83. Hughes AR, Spreen WR, Mosteller M, et al. Pharmacogenetics of hypersensitivity to abacavir: from PGx hypothesis to confirmation to clinical utility. Pharmacogenomics J. 2008;8(6): 365-374.

84. Nelson MR, Bacanu SA, Mosteller M, et al. Genome-wide approaches to identify pharmacogenetic contributions to adverse drug reactions. Pharmacogenomics J. 2009;9(1):23-33.

85. Klein TE, Altman RB, Eriksson N, et al. Estimation of the warfarin dose with clinical and pharmacogenetic data. $N$ Engl J Med. 2009; 360(8):753-764.

86. Auffray C, Charron D, Hood L. Predictive, preventive, personalized and participatory medicine: back to the future. Genome Med. 2010;2(8):57.

87. PharmGkb [database on the Internet]. Available from: http://www. pharmgkb.org/. Accessed January 6, 2012.

88. Moncada S, Higgs A. The L-arginine-nitric oxide pathway. $N$ Engl J Med. 1993;329(27):2002-2012.

89. Dudzinski DM, Michel T, Colman RW, et al. The vascular biology of nitric oxide and nitric oxide synthases. In: Colman RW, Clowes AW, Goldhaber SZ, et al. editors. Hemostasis and Thrombosis: Basic Prinicples and Clinical Practice. 5th ed. Philadelphia, PA: Lippincott Williams and Wilkins; 2005:653-666.

90. Cooke JP, Dzau VJ. Nitric oxide synthase: role in the genesis of vascular disease. Annu Rev Med. 1997;48:489-509. 
91. Sandrim VC, Palei AC, Metzger IF, Gomes VA, Cavalli RC, TanusSantos JE. Nitric oxide formation is inversely related to serum levels of antiangiogenic factors soluble fms-like tyrosine kinase-1 and soluble endogline in preeclampsia. Hypertension. 2008;52(2): 402-407.

92. Gryglewski RJ, Palmer RM, Moncada S. Superoxide anion is involved in the breakdown of endothelium-derived vascular relaxing factor. Nature. 1986;320(6061):454-456.

93. Vasquez-Vivar J, Kalyanaraman B, Martasek P, et al. Superoxide generation by endothelial nitric oxide synthase: the influence of cofactors. Proc Natl Acad Sci U S A. 1998;95(16):9220-9225.

94. Marsden PA, Heng HH, Scherer SW, et al. Structure and chromosomal localization of the human constitutive endothelial nitric oxide synthase gene. J Biol Chem. 1993;268(23):17478-17488.

95. Miyahara K, Kawamoto T, Sase K, et al. Cloning and structural characterization of the human endothelial nitric-oxide-synthase gene. Eur J Biochem. 1994;223(3):719-726.

96. Sandrim VC, Palei AC, Cavalli RC, et al. Vascular endothelial growth factor genotypes and haplotypes are associated with preeclampsia but not with gestational hypertension. Mol Hum Reprod. 2009;15(2):115-120.

97. Cooke GE, Doshi A, Binkley PF. Endothelial nitric oxide synthase gene: prospects for treatment of heart disease. Pharmacogenomics. 2007;8(12):1723-1734.

98. Pereira TV, Rudnicki M, Cheung BM, et al. Three endothelial nitric oxide (NOS3) gene polymorphisms in hypertensive and normotensive individuals: meta-analysis of 53 studies reveals evidence of publication bias. J Hypertens. 2007;25(9):1763-1774.

99. Silva PS, Lacchini R, Gomes Vde A, Tanus-Santos JE. Pharmacogenetic implications of the eNOS polymorphisms for cardiovascular action drugs. Arq Bras Cardiol. 2011;96(2):e27-e34.

100. Kumasawa K, Ikawa M, Kidoya H, et al. Pravastatin induces placental growth factor (PGF) and ameliorates preeclampsia in a mouse model. Proc Natl Acad Sci U S A. 2011;108(4):1451-1455.

101. Ahmed A. New insights into the etiology of preeclampsia: identification of key elusive factors for the vascular complications. Thromb Res. 2011;127 Suppl 3:S72-S75.

102. Abe K, Nakayama M, Yoshimura M, et al. Increase in the transcriptional activity of the endothelial nitric oxide synthase gene with fluvastatin: a relation with the $-786 \mathrm{~T}>\mathrm{C}$ polymorphism. Pharmacogenet Genomics. 2005;15(5):329-336.

103. Nagassaki S, Sertorio JT, Metzger IF, Bem AF, Rocha JB, TanusSantos JE. eNOS gene T-786C polymorphism modulates atorvastatininduced increase in blood nitrite. Free Radic Biol Med. 2006;41(7): 1044-1049.

104. Souza-Costa DC, Sandrim VC, Lopes LF, Gerlach RF, Rego EM, Tanus-Santos JE. Anti-inflammatory effects of atorvastatin: modulation by the T-786C polymorphism in the endothelial nitric oxide synthase gene. Atherosclerosis. 2007;193(2):438-444.

105. Kunnas TA, Lehtimaki T, Laaksonen R, et al. Endothelial nitric oxide synthase genotype modulates the improvement of coronary blood flow by pravastatin: a placebo-controlled PET study. J Mol Med (Berl). 2002;80(12):802-807.

106. Liljedahl U, Karlsson J, Melhus H, et al. A microarray minisequencing system for pharmacogenetic profiling of antihypertensive drug response. Pharmacogenetics. 2003;13(1):7-17.

107. Duley L, Henderson-Smart DJ, Meher S. Drugs for treatment of very high blood pressure during pregnancy. Cochrane Database Syst Rev. 2006;3:CD001449.

108. Lemke LE, McQueen CA. Acetylation and its role in the mutagenicity of the antihypertensive agent hydralazine. Drug Metab Dispos. 1995;23(5):559-565.

109. Sim E, Lack N, Wang CJ, et al. Arylamine N-acetyltransferases: structural and functional implications of polymorphisms. Toxicology. 2008;254(3):170-183.
110. Barnea ER, Fakih H, Oelsner G, Walner S, DeCherney AH, Naftolin F. Effect of antihypertensive drugs on catechol-O-methyltransferase and monoamine oxidase activity in human term placental explants. Gynecol Obstet Invest. 1986;21(3):124-130.

111. Askie LM, Duley L, Henderson-Smart DJ, Stewart LA. Antiplatelet agents for prevention of pre-eclampsia: a meta-analysis of individual patient data. Lancet. 2007;369(9575):1791-1798.

112. Shimokawa T, Smith WL. Prostaglandin endoperoxide synthase. The aspirin acetylation region. J Biol Chem. 1992;267(17):12387-12392.

113. Shantsila E, Watson T, Lip GY. Aspirin resistance: what, why and when? Thromb Res. 2007;119(5):551-554.

114. Angiolillo DJ. Variability in responsiveness to oral antiplatelet therapy. Am J Cardiol. 2009;103(Suppl 3):27A-34A.

115. Gum PA, Kottke-Marchant K, Poggio ED, et al. Profile and prevalence of aspirin resistance in patients with cardiovascular disease. $\mathrm{Am} \mathrm{J}$ Cardiol. 2001;88(3):230-235.

116. Mueller MR, Salat A, Stangl P, et al. Variable platelet response to low-dose ASA and the risk of limb deterioration in patients submitted to peripheral arterial angioplasty. Thromb Haemost. 1997;78(3): 1003-1007.

117. Tantry US, Bliden KP, Gurbel PA. Overestimation of platelet aspirin resistance detection by thrombelastograph platelet mapping and validation by conventional aggregometry using arachidonic acid stimulation. J Am Coll Cardiol. 2005;46(9):1705-1709.

118. Gurbel PA, Bliden KP, DiChiara J, et al. Evaluation of dose-related effects of aspirin on platelet function: results from the AspirinInduced Platelet Effect (ASPECT) study. Circulation. 2007;115(25): 3156-3164.

119. Cambria-Kiely JA, Gandhi PJ. Possible mechanisms of aspirin resistance. J Thromb Thrombolysis. 2002;13(1):49-56.

120. Bhatt DL. Aspirin resistance: more than just a laboratory curiosity. J Am Coll Cardiol. 2004;43(6):1127-1129.

121. Wang TH, Bhatt DL, Topol EJ. Aspirin and clopidogrel resistance: an emerging clinical entity. Eur Heart J. 2006;27(6):647-654.

122. Halushka MK, Walker LP, Halushka PV. Genetic variation in cyclooxygenase 1: effects on response to aspirin. Clin Pharmacol Ther. 2003;73(1):122-130.

123. Gonzalez-Conejero R, Rivera J, Corral J, Acuna C, Guerrero JA, Vicente V. Biological assessment of aspirin efficacy on healthy individuals: heterogeneous response or aspirin failure? Stroke. 2005;36(2): 276-280.

124. Goodman T, Sharma P, Ferro A. The genetics of aspirin resistance. Int J Clin Pract. 2007;61(5):826-834.

125. Goodman T, Ferro A, Sharma P. Pharmacogenetics of aspirin resistance: a comprehensive systematic review. Br J Clin Pharmacol. 2008;66(2):222-232.

126. Michelson AD, Furman MI, Goldschmidt-Clermont P, et al. Platelet GP IIIa Pl(A) polymorphisms display different sensitivities to agonists. Circulation. 2000;101(9):1013-1018.

127. Cooke GE, Bray PF, Hamlington JD, Pham DM, GoldschmidtClermont PJ. P1A2 polymorphism and efficacy of aspirin. Lancet. 1998;351(9111):1253.

128. Corral J, Gonzalez-Conejero R, Rivera J, Ortuno F, Aparicio P, Vicente V. Role of the $807 \mathrm{C} / \mathrm{T}$ polymorphism of the alpha2 gene in platelet GP Ia collagen receptor expression and function - effect in thromboembolic diseases. Thromb Haemost. 1999;81(6):951-956.

129. Belfort MA. The effect of magnesium sulphate on blood flow velocity in the maternal retina in mild pre-eclampsia: a preliminary colour flow Doppler study. Br J Obstet Gynaecol. 1992;99(8): 641-645.

130. Sadeh M. Action of magnesium sulfate in the treatment of preeclampsia-eclampsia. Stroke. 1989;20(9):1273-1275.

131. Duley L, Gulmezoglu AM, Henderson-Smart DJ. Magnesium sulphate and other anticonvulsants for women with pre-eclampsia. Cochrane Database Syst Rev. 2003;2:CD000025. 
132. Witlin AG, Friedman SA, Sibai BM. The effect of magnesium sulfate therapy on the duration of labor in women with mild preeclampsia at term: a randomized, double-blind, placebo-controlled trial. Am JObstet Gynecol. 1997;176(3):623-627.

133. Altman D, Carroli G, Duley L, et al. Do women with pre-eclampsia, and their babies, benefit from magnesium sulphate? The Magpie Trial: a randomised placebo-controlled trial. Lancet. 2002;359(9321): $1877-1890$

134. Lipsitz PJ. The clinical and biochemical effects of excess magnesium in the newborn. Pediatrics. 1971;47(3):501-509.

135. Magee LA, Abalos E, von Dadelszen P, Sibai B, Easterling T, Walkinshaw $\mathrm{S}$. How to manage hypertension in pregnancy effectively. Br J Clin Pharmacol. 2011;72(3):394-401.

136. Bremer T, Man A, Kask K, Diamond C. CACNA1C polymorphisms are associated with the efficacy of calcium channel blockers in the treatment of hypertension. Pharmacogenomics. 2006;7(3):271-279.

137. Beitelshees AL, Navare H, Wang D, et al. CACNA1C gene polymorphisms, cardiovascular disease outcomes, and treatment response. Circ Cardiovasc Genet. 2009;2(4):362-370.
138. Langaee TY, Gong Y, Yarandi HN, et al. Association of CYP3A5 polymorphisms with hypertension and antihypertensive response to verapamil. Clin Pharmacol Ther. 2007;81(3):386-391.

139. Beitelshees AL, Gong Y, Wang D, et al. KCNMB1 genotype influences response to verapamil SR and adverse outcomes in the INternational VErapamil SR/Trandolapril STudy (INVEST). Pharmacogenet Genomics. 2007;17(9):719-729.

140. Pacanowski MA, Gong Y, Cooper-Dehoff RM, et al. beta-adrenergic receptor gene polymorphisms and beta-blocker treatment outcomes in hypertension. Clin Pharmacol Ther. 2008;84(6):715-721.

141. Lynch AI, Boerwinkle E, Davis BR, et al. Pharmacogenetic association of the NPPA T2238C genetic variant with cardiovascular disease outcomes in patients with hypertension. JAMA. 2008;299(3):296-307.

142. The Confidential Enquiry into Maternal and Child Health (CEMACH). Saving Mothers' Lives: Reviewing Maternal Deaths to Make Motherhood Safer - 2003-2005. The Seventh Report on Confidential Enquiries into Maternal Deaths in the United Kingdom. Lewis G, editor. London: CEMACH; 2007.
Pharmacogenomics and Personalized Medicine

\section{Publish your work in this journal}

Pharmacogenomics and Personalized Medicine is an international, peerreviewed, open access journal characterizing the influence of genotype on pharmacology leading to the development of personalized treatment programs and individualized drug selection for improved safety, efficacy and sustainability. This journal is indexed on the American Chemical

\section{Dovepress}

Society's Chemical Abstracts Service (CAS). The manuscript management system is completely online and includes a very quick and fair peer-review system, which is all easy to use. Visit http://www.dovepress. $\mathrm{com} /$ testimonials.php to read real quotes from published authors.

Submit your manuscript here: http://www.dovepress.com/pharmacogenomics-and-personalized-medicine-journal 